This document was prepared in conjunction with work accomplished under Contract No. DE-AC09-96SR18500 with the U.S. Department of Energy.

This work was prepared under an agreement with and funded by the U.S. Government. Neither the U. S. Government or its employees, nor any of its contractors, subcontractors or their employees, makes any express or implied: 1 . warranty or assumes any legal liability for the accuracy, completeness, or for the use or results of such use of any information, product, or process disclosed; or 2 . representation that such use or results of such use would not infringe privately owned rights; or 3 . endorsement or recommendation of any specifically identified commercial product, process, or service. Any views and opinions of authors expressed in this work do not necessarily state or reflect those of the United States Government, or its contractors, or subcontractors. 
PVP2008-61015

\section{Comparison of Response of 9977 Test Packages to Analytical Results}

\author{
Allen C. Smith \\ Savannah River National Laboratory \\ Washington Savannah River Company \\ Aiken, South Carolina 29808 \\ (803) 725 2943, allen.smith@srnml.doe.gov
}

\author{
Tsu-Te Wu \\ Savannah River National Laboratory \\ Washington Savannah River Company \\ Aiken, South Carolina 29808 \\ (803) 725 8201, tsu-te.wu@srnl.doe.gov
}

\begin{abstract}
Each of the hypothetical accident test cases for the 9977 prototypes was included in the battery of finite element structural analyses performed for the package. Comparison of the experimental and analytical results provides a means of confirming that the analytical model correctly represents the physical behavior of the package. The ability of the analytical model to correctly predict the performance of the foam overpack material for the crush test is of particular interest. The dissipation of energy in the crushing process determines the deceleration of the package upon impact and the duration of the impact. In addition, if the analytical model correctly models the foam behavior., the predicted deformation of the package will match that measured on the test articles. This study compares the deformations of the test packages with the analytical predictions.

In addition, the impact acceleration and impact duration for the test articles are compared with those predicted by the analyses.
\end{abstract}

\section{INTRODUCTION}

In the development of a radioactive materials packaging, the design is typically subjected to analyses for all NCT and HAC performance requirements. Test packages are then fabricated and subjected to the same test sequence. Comparison of the experimental and analytical results assists in understanding the response of the package to the testing. In addition, it provides a means of confirming that the analyses correctly represent the performance of the package. In the
NCT and HAC tests of the 9977 General Purpose Fissile Package, the test packages were measured, photographed and radiographed at each stage of the test sequence. The structural tests were also recorded using high speed video. Each of the hypothetical accident test cases was part of the finite element structural analyses performed for the package.

Polyurethane foam was selected for the overpack for the 9977, to provide impact and thermal protection for the containment vessel. The ability of the analytical model to correctly predict the crushing performance of the foam overpack material is of particular interest. The dissipation of energy in the crushing process determines the deceleration of the package upon impact and the duration of the impact. In addition, if the analytical model correctly models the foam behavior, the predicted deformation of the package will match that measured on the test articles.

This study compares the response of the test packages to the analytical predictions.

In addition, the impact acceleration and impact duration for the test articles are compared with those predicted by the analyses.

\section{GPFP DESIGN}

The GPFP is conceptually similar to other drum packages, with containment vessel contained within an overpack that provides protection against impact and fire. The GPFP incorporates the proven Chalfant containment vessel design. The Chalfant design is space efficient and very robust. 


\section{Cases addressed.}

The study considers two orientations that challenge the foam overpack in different ways. The axial, bottom down drop results in maximum deceleration for the package, because it involves the full cross section of the overpack material throughout the event. The horizontal drop results in lower impact acceleration, because the cross section of overpack material involved increases progressively as the cord of the deformed region of the cylindrical drum. The horizontal drop imparts maximum lateral loads to the containment vessel closure and maximum transverse loads to the shell and closure of the containment vessel. The horizontal drop and crush are most challenging (i.e., result in the most extensive fracturing) for the foam overpack.

The study compares deformations, impact acceleration and impact duration for these two cases.

\section{Post Drop Dimensional Comparison}

Digital radiographs were made of each test package at each stage of the test program. Pre test radiographs were made with and without the dummy contents. Subsequent radiographs were made following each test. The packages were destructively examined following the thermal test. The results of these examinations were reported in the Test Report, Reference 1 and in the SARP. Reference 2.

Figures 1 and 2 compare the calculated response of package SN-5 with the radiograph of the package for the axial, bottomdown drop test. The comparison shows good qualitative and quantitative agreement between the experimental and analytical results. The radiographs show the flattening of the dished drum bottom and the buckle in the side of the drum, immediately above the chime predicted by the analysis.

In the physical test of SN-5, the shell is deformed relative to the foam, flattening the bottom offset around the entire circumference and flattening the remainder of the dished bottom across its diameter. On three quadrants, this resulted in the buckling of the shell immediately above the chime. On the fourth quadrant, the bottom offset was flattened, with no change in shell height on that side.

These same features are predicted by the analytical results. The analytical model predicted that the bottom offset would be flattened and the bottom rim would be flattened and buckled outward, uniformly, around the full circumference of the drum. This difference with respect to the bottom rim is attributed to the idealized representation of the package and test in the mathematical model and the minor variations in configuration and impact angle present in the physical test. Regardless of the differences in structural details, the bottom drop resulted in deformation of the metal shell to the point where the cross section of the foam was engaged, in both analytical and experimental cases. At that point, the impact was absorbed by the foam, with minor, local crushing.

Table 1 gives the measured and calculated drum heights for the $30 \mathrm{ft}$, axial, bottom down drop of package SN-5. The experimental values are the height changes at reference locations on the surface of the drum, $90^{\circ}$ apart. The bottom offset is the average displacement, across the area of bottom. The displacement for the analytical case is primarily due to deformation of the curved rim at the bottom. The best estimate of the deformation experienced by package SN-5 is judged to be the average of the three displacements where the shell moved with the foam, 0.52 in.

Table 1. Comparison for SN-5 Dimensional Changes

\begin{tabular}{|c|c|c|c|c|c|}
\hline & \multicolumn{4}{|c|}{$\begin{array}{c}\text { Drum Height } \\
\text { Measurements, in. }\end{array}$} & $\begin{array}{l}\text { Bottom Offset, } \\
\text { in. }\end{array}$ \\
\hline Experimental & 0.375 & 0.5 & 0.69 & 0.0 & 0.6 avg. \\
\hline Analytical & \multicolumn{4}{|c|}{0.495} & 0.66 \\
\hline
\end{tabular}

The corresponding results for the horizontal drop test of package SN-3 shows good qualitative agreement between the experimental and analytical results for this case, also. The diametral flattening of the chime, the top rim and the rolling rings, where impact occurred, conforms to the analytical predictions. The overall deformations are compared in Table 2.

Table 2. Dimensional Comparison for SN-3

\begin{tabular}{|l|l|l|l|l|}
\hline & \multicolumn{3}{|l|}{ Measured for SN-3 } & \multicolumn{2}{l|}{ Calculated } \\
\hline & Top & Bottom & $\begin{array}{l}\text { Mid } \\
\text { Height }\end{array}$ & Bottom \\
\hline $\begin{array}{l}\text { Undeformed } \\
\text { Diameter }\end{array}$ & 18.25 & 18.25 & 18.3 & 18.3 \\
\hline $\begin{array}{l}\text { After 30 ft } \\
\text { Drop }\end{array}$ & 18.25 & 17.875 & 18.22 & 18.17 \\
\hline $\begin{array}{l}\text { After 30 ft } \\
\text { Drop and 30 ft } \\
\text { Crush }\end{array}$ & 18.25 & 14.5 & 17.93 & 16.54 \\
\hline
\end{tabular}

\section{Initial deceleration of Bottom Down drop from analytical results.}

In the analyses, the kinetic energy is calculated for the package and presented in the figures titled "Time-History Plot of Energy" for each case (Figures 3 and 4). The corresponding deceleration can be calculated from the slope of the kinetic energy curve.

$\mathrm{a}=(\mathrm{dKE} / \mathrm{dt}) / \mathrm{mv}$

$\mathrm{dKE} / \mathrm{dt}$ can be obtained from results of the $30 \mathrm{ft}$ drop analyses. The mass used for analyses is typical of drop weight of packages $\left(\mathrm{m}_{\text {analysis }}=350 \mathrm{lbm}\right.$ vs. $\left.\mathrm{m}_{\text {test }}=340 \mathrm{lbm}\right)$. The velocity 
of the package after a drop of $30 \mathrm{ft}$, i.e., just before impact, is $527.5 \mathrm{in} / \mathrm{sec}$ or $44 \mathrm{ft} / \mathrm{sec}$. (from $\left.\mathrm{v}_{0}=(2 \mathrm{gh})^{1 / 2}\right)$.

The kinetic energy on "Time History Plot of Energy" curves from analyses is $60 \times 10^{3}$ in-lbf, $(5,000 \mathrm{ft} \mathrm{lb})$ and is half the package KE. (because the analytical model was a half model). So, the total package kinetic energy for the analytical case is $10,000 \mathrm{ft}-\mathrm{lb}$.

For a package dropped from a height of $30 \mathrm{ft}$, the kinetic energy for the corresponding test case is:

$\mathrm{KE}=(1 / 2) \mathrm{mv}^{2}=10,522 \mathrm{ft}-\mathrm{lbf}$

\section{Impact Deceleration for Test Packages}

The deceleration of the test packages following impact, is estimated from the motion of the center of gravity (distance traveled in the time elapsed) as determined from the high speed video of the drop test.

The analytical results show that the change in kinetic energy during the initial part of the impact is very nearly linear (i.e., constant slope). For constant, or average deceleration, the linear motion of the package is related to the deceleration by the equation:

$\mathrm{a}=2\left(\mathrm{~s}-\mathrm{v}_{0} \mathrm{t}\right) /\left(\mathrm{t}^{2}\right)$

where: $\mathrm{s}$ is the distance traveled

$\mathrm{s}_{0}$ is the initial position $\left(\mathrm{s}_{0}=0\right)$

$\mathrm{v}_{0}=$ initial velocity $\left(\mathrm{v}_{0}=527.5 \mathrm{in} / \mathrm{sec}\right)$

\section{Comparison for SN-5 (bottom down impact).}

The time history for kinetic energy from the analyses for SN-5, this is given in Figure 1:

$\Delta \mathrm{KE} / \Delta \mathrm{t}=20 \times 10^{6} \mathrm{in}-\mathrm{lbf} / \mathrm{sec}$

$\Delta \mathrm{KE} / \Delta \mathrm{t}_{\text {full package }}=40 \times 10^{6} \mathrm{in}-\mathrm{lbf} / \mathrm{sec}$

The corresponding initial deceleration from analysis is:

$\mathrm{a}=(\Delta \mathrm{KE} / \Delta \mathrm{t}) / \mathrm{mv}_{0}=6976 \mathrm{ft} / \mathrm{sec}^{2}$, or $216 \mathrm{~g}$

Video Data for SN-5

The positions of the package were determined by measuring the motion of the package, frame-by-frame, against the backboard grid. The grid has 6 in. squares with smaller, 2 in. squares, in the lower four rows. The high speed video provides a time mark for each frame.

\begin{tabular}{|l|l|l|}
\hline Time(ms) & Position & Notes \\
\hline 2310 & $\begin{array}{l}\text { Top L corner 1 to } \\
1.25 \text { in. above } \\
\text { Line5 }\end{array}$ & Falling \\
\hline 2308 & $\begin{array}{l}\text { Top corner at } \\
\text { Line 5 }\end{array}$ & Already in contact \\
\hline 2306 & $\begin{array}{l}\text { Top corner 1 in. } \\
\text { below Line5 }\end{array}$ & Crushing \\
\hline 2304 & $\begin{array}{l}\text { top corner about } \\
1 \text { in. below L5 }\end{array}$ & Package nearly stationary. \\
\hline 2302 & & Rebounding \\
\hline 2300 & & \\
\hline
\end{tabular}

The package was falling at 2310 (top corner 1 to 1.5 small squares above Line 5) and already in contact at 2308 (top corner at Line 5). Measurement indicate that the package made contact at approximately $2309 \mathrm{~ms}$. At initial contact the reference point, the top left corner, would have been $0.5 \mathrm{in}$. above Line 5.

The total distance traveled by the corner from contact to its minimum height was:

$\Delta \mathrm{s}=1.5 \mathrm{in}$.

The time elapsed was: $\Delta \mathrm{t}=2309-2304=5 \mathrm{~ms}$.

The deceleration is:

$\mathrm{a}_{\exp }=2\left(\mathrm{~s}-\mathrm{v}_{0} \mathrm{t}\right) /\left(\mathrm{t}^{2}\right)-235.5 \mathrm{~g}$

As a sensitivity check, the calculation was repeated assuming the displacement takes place in $4 \mathrm{~ms}$. This calculation yields a deceleration of $-197 \mathrm{~g}$.

\section{Comparison of time to end of motion (minimum kinetic energy) for initial impact.}

Analytical results show that the minimum KE occurs $5 \mathrm{~ms}$ after initial impact.

From video review:

The time step for minimum height occurs at 2304. Time interval between initial contact and minimum height is: $2309-$ $2304=5 \mathrm{~ms}$.

\section{Comparison for SN-3 (horizontal impact)}

The time history for kinetic energy from the analyses for $\mathrm{SN}-3$, this is given in Figure 2:

$\Delta \mathrm{KE} / \Delta \mathrm{t}=34 \times 10^{6} \mathrm{in}-\mathrm{lbf} / \mathrm{sec}$

Initial deceleration from analysis is: 
$\mathrm{a}=(\Delta \mathrm{KE} / \Delta \mathrm{t}) / \mathrm{mv}_{0}=184 \mathrm{~g}$

Video Data for SN-3

The positions of the package were determined by measuring the motion of the package, frame-by-frame, against the backboard grid. The grid has 6 in. squares with smaller, 2 in. squares, in the lower four rows. The high speed video provides a time mark for each frame.

The package rim has just made contact with the target at time mark 2300. At this point, the reference point (the mid-point of the drum side directly above the center of gravity) is $1 \mathrm{in}$. below Line 2. The minimum position occurs at time mark 2294, with the reference point 3 in. below Line 2.

The total distance traveled by the reference point from contact to its minimum height was:

$\Delta \mathrm{s}=2$ in.

The time elapsed was:

$\Delta \mathrm{t}=2300-2294=6 \mathrm{~ms}$.

The deceleration is:

$\mathrm{a}_{\exp }=-168 \mathrm{~g}$

As a sensitivity check, the calculation was repeated assuming the displacement of 2.25 in. takes place in $6 \mathrm{~ms}$ yielding a deceleration of -131 g. For a displacement of 2 in. and a duration of $5 \mathrm{~ms}$, the deceleration would be $-132 \mathrm{~g}$.

\begin{tabular}{|c|c|c|}
\hline Time(ms) & Position & Notes \\
\hline 2300 & $\begin{array}{l}\text { Top of package } 2 \text { in. } \\
\text { below Line } 2, \\
\text { Bottom at Line 2, } \\
\text { Center } 1 \text { in. below } \\
\text { L2 }\end{array}$ & $\begin{array}{l}\text { Top of package just } \\
\text { contacts test surface. }\end{array}$ \\
\hline 2298 & $\begin{array}{l}\text { Center } 2 \text { in. below } \\
\text { Line } 2\end{array}$ & Package rotates \\
\hline 2296 & $\begin{array}{l}\text { Top and Bottom of } \\
\text { package } 3 \text { in. below } \\
\text { Line } 2\end{array}$ & Bottom contacts surface. \\
\hline 2294 & $\begin{array}{l}\text { Center } 3 \text { in. } \text { below } \\
\text { L2, Top } 2 \frac{1}{2} \text { below } \\
\text { L2, Bottom } 3 \frac{1}{2} \text { in } \\
\text { below L2 }\end{array}$ & $\begin{array}{l}\text { Minimum height of } \\
\text { package CG. No vertical } \\
\text { motion at top of package. }\end{array}$ \\
\hline 2292 & $\begin{array}{l}\text { Top } 2 \frac{1 / 2}{2} \text { in. below } \\
\text { L2, Bottom } 4 \text { in } \\
\text { below Line2 }\end{array}$ & $\begin{array}{l}\text { Package almost stationary } \\
\text { at both ends. }\end{array}$ \\
\hline 2290 & & Rebounding \\
\hline 2288 & & Rebounding \\
\hline 1884 & 5 sq above floor. & $\begin{array}{l}\text { Maximum centerline } \\
\text { height. }\end{array}$ \\
\hline
\end{tabular}

\section{Comparison of time to end of motion (minimum kinetic energy) for initial impact.}

Analytical results (from Figure 60):

Minimum KE occurs $4.12 \mathrm{~ms}$ after initial impact.

From video review:

The time for minimum height is 2294. Time interval between initial contact (at the top rim of the package) and minimum height is: $2300-2294=6 \mathrm{~ms}$. However, for this test, the package was $2.5^{\circ}$ from horizontal, with the top down, at impact. Although this does not alter the energy dissipated, it does affect the timing of the package response. The bottom contacts the test surface at 2296, $4 \mathrm{~ms}$ after the top. Using the average of top and bottom contact times, the package impacts at time mark 2298. The time interval between this time and the minimum height is: $2298-2294=4 \mathrm{~ms}$.

A corollary effect of longer time for the impact process is somewhat lower deceleration of the package.

\section{Conclusions}

The results of the analyses compare well with the results of the tests. For the bottom down drop, SN-5, the calculated deceleration was $216 \mathrm{~g}$, compared to a test deceleration of 200 to $236 \mathrm{~g}$. The duration of the impact (time to minimum Kinetic Energy) was $5 \mathrm{~ms}$, for both analysis and test.

For the horizontal drop, SN-3, the calculated deceleration was $184 \mathrm{~g}$, compared to a test deceleration of $168 \mathrm{~g}$. The duration of the impact (time to minimum Kinetic Energy) was $4 \mathrm{~ms}$, for both analysis and test.

The comparison confirms that the analyses are representative of the physical test results. The results validate the finite element analysis of the drop tests. In addition, the constitutive model used for the polyurethane foam is validated by the comparison.

\section{References}

1. Gelder, L. F. and May, C. G., "9977 General Purpose Fissile Package Prototype Testing”, SRNL Report M-TRT-A-00007, Rev. 1, May, 2006.

2. "Safety Analysis Report for Packaging Model 9977”, SRNL Report S-SARP-G-00001, May, 2006.

Goods, S. H., Neuschwanger, C. L., Henderson, C and Skala, D. M., "Mechanical Properties and Energy Absorption 
Characteristics of a Polyurethane Foam, Sandia Report SAND97-8490, March 1997.

$($ ALLKE $=$ kinetic energy; ALLIE $=$ internal energy; ALLPD $=$ plastic strain energy; ALLSE = elastic strain energy; ALLAE = artificial energy)

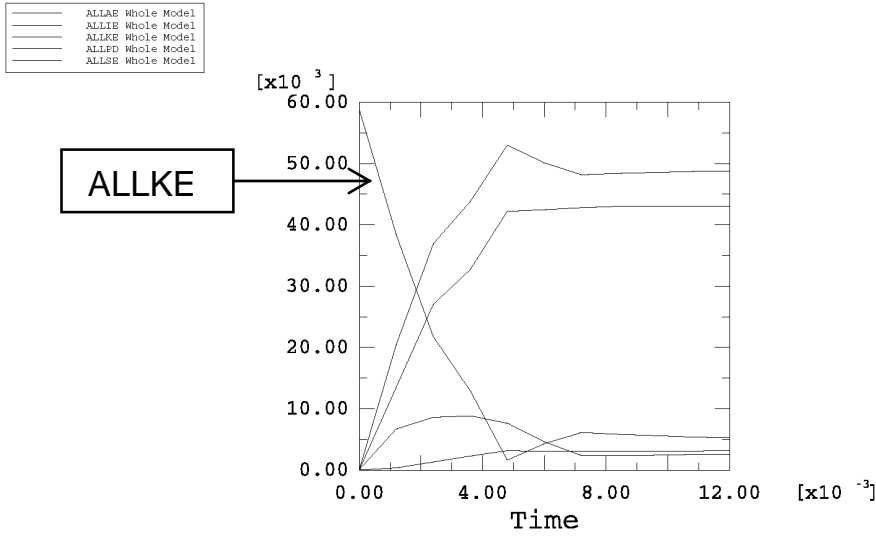

Figure 1 - Time-History Plot of Energy during Drum Bottom Down - 30-ft Drop ( $\left.75^{\circ} \mathrm{F}\right)$

$($ ALLKE $=$ kinetic energy; ALLIE $=$ internal energy; ALLPD $=$ plastic strain energy; ALLSE = elastic strain energy; ALLAE = artificial energy)
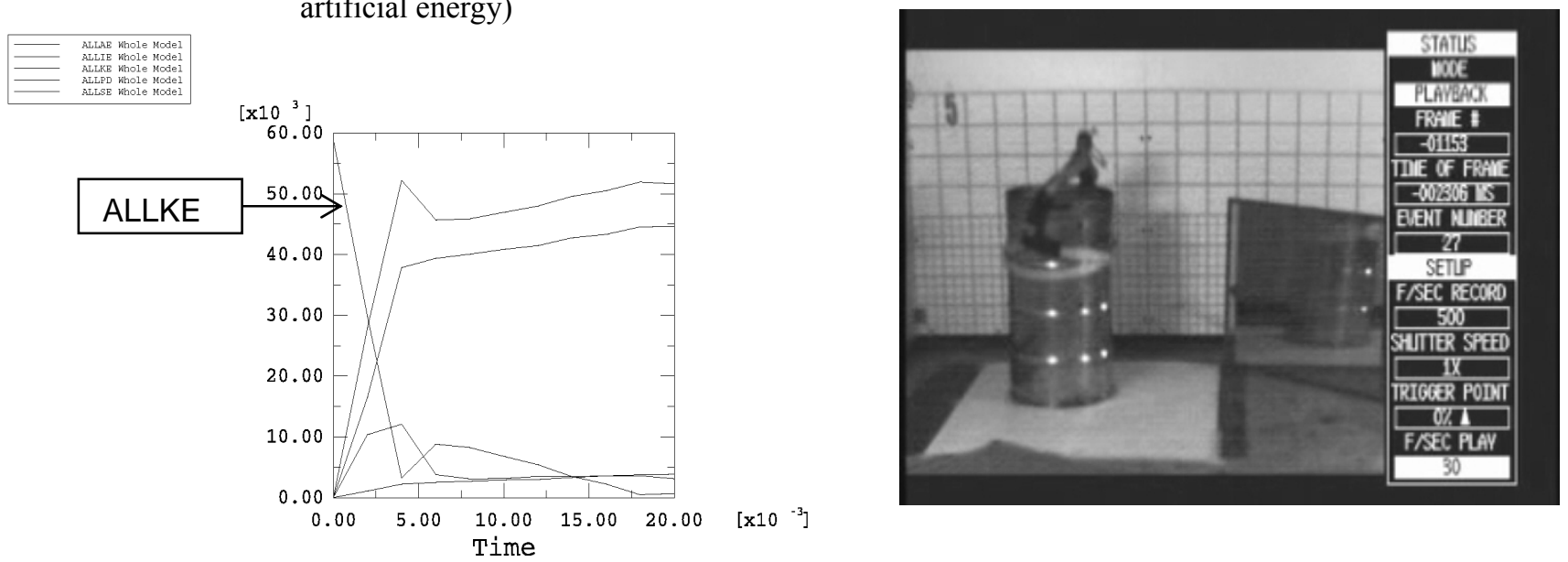

Figure 2 - Time-History Plot of Energy during Drum on Side - 30-ft Drop Simulation (-20 $\left.{ }^{\circ} \mathrm{F}\right)$ 

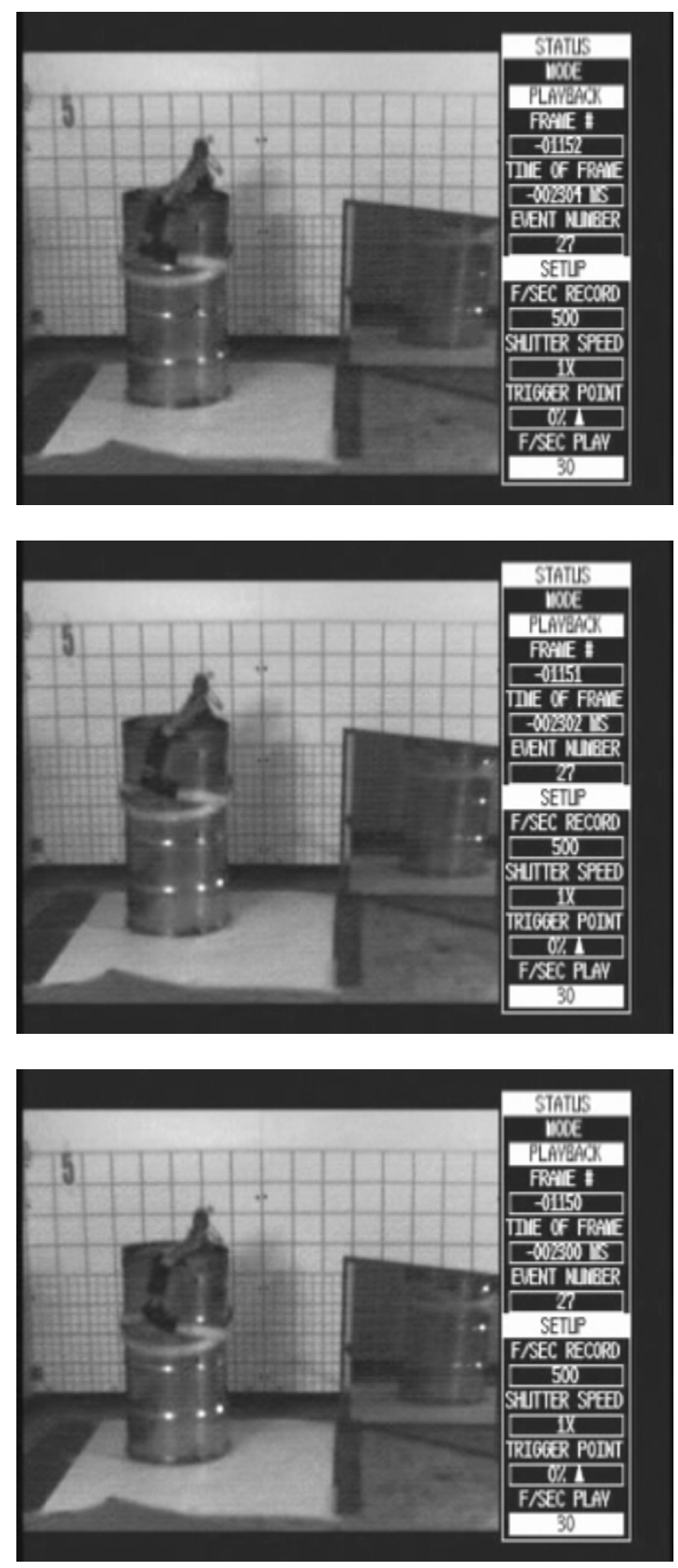
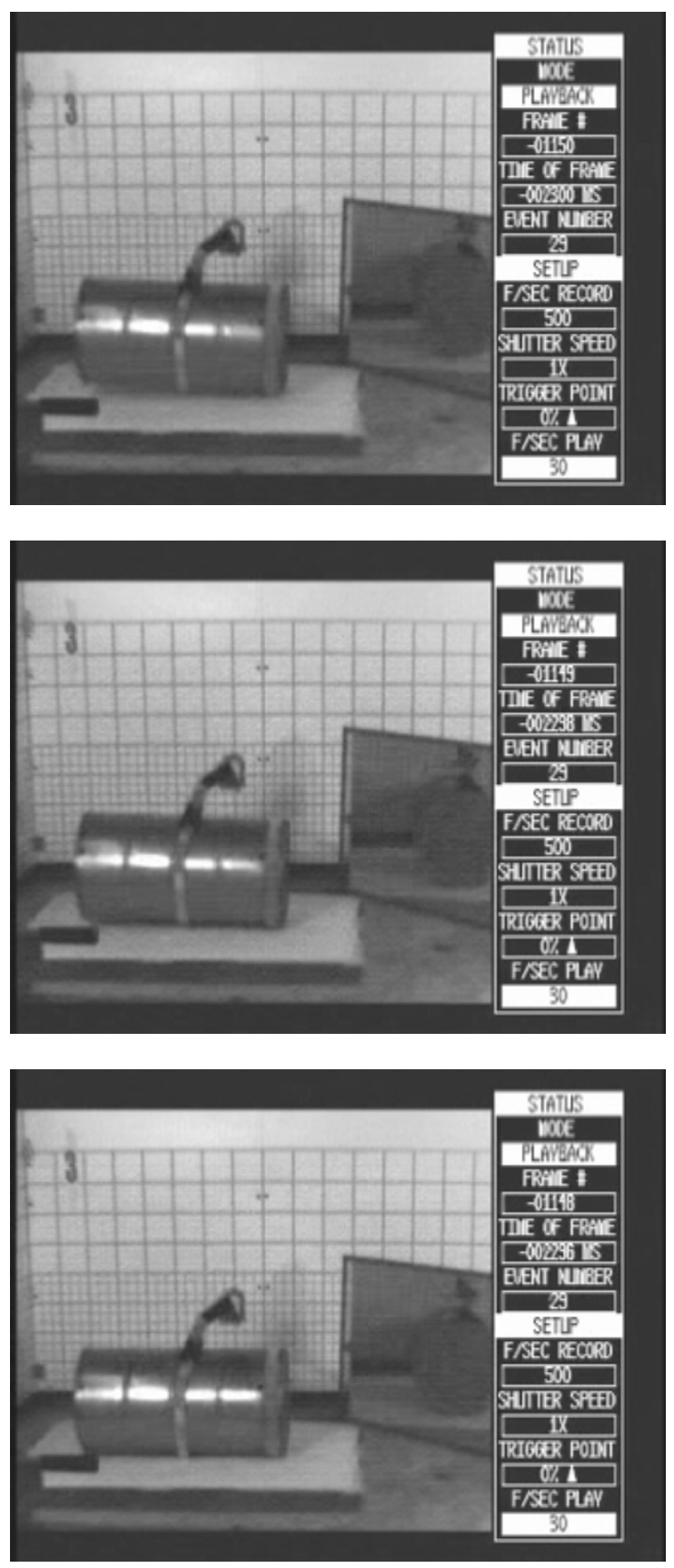

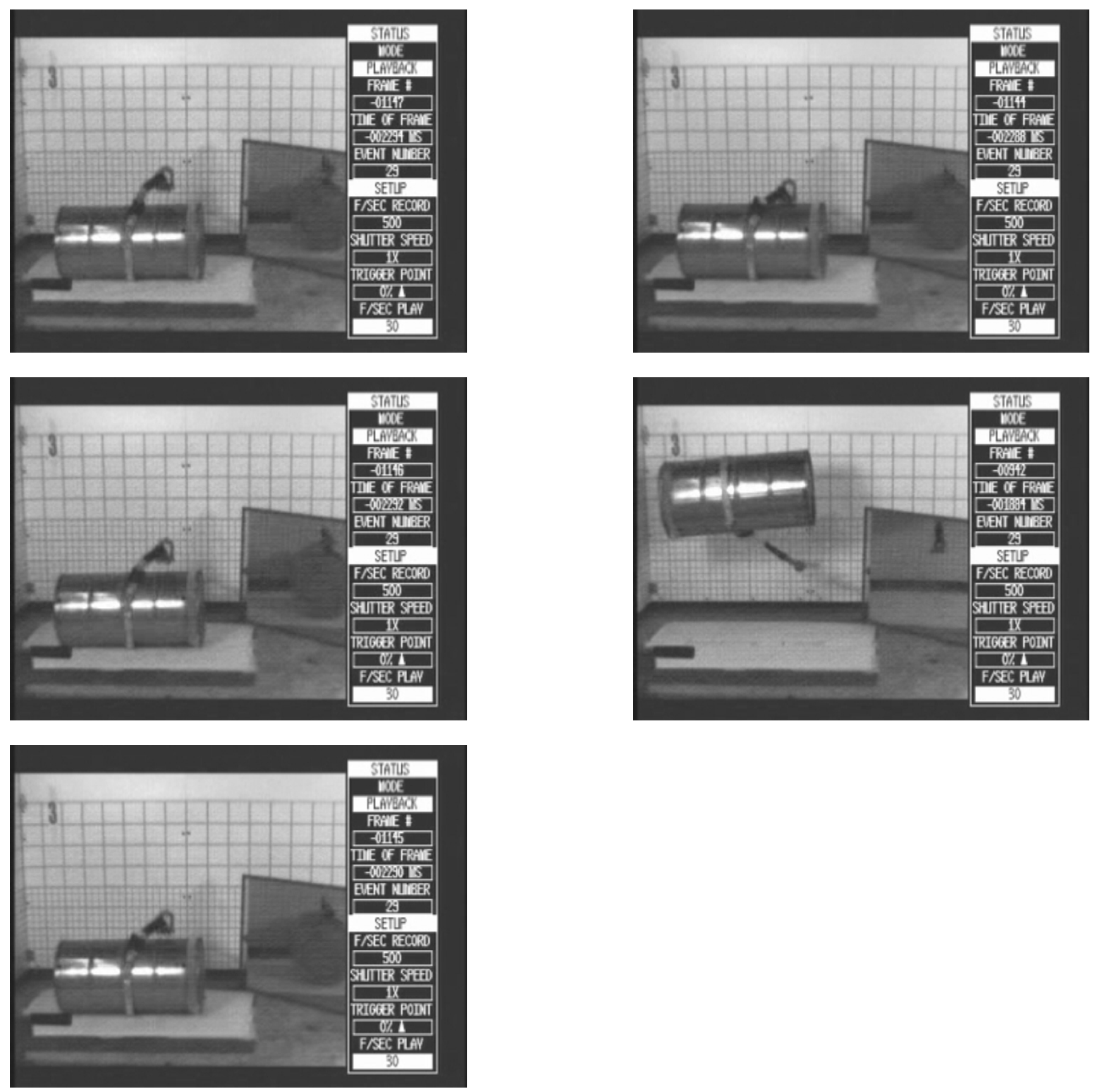

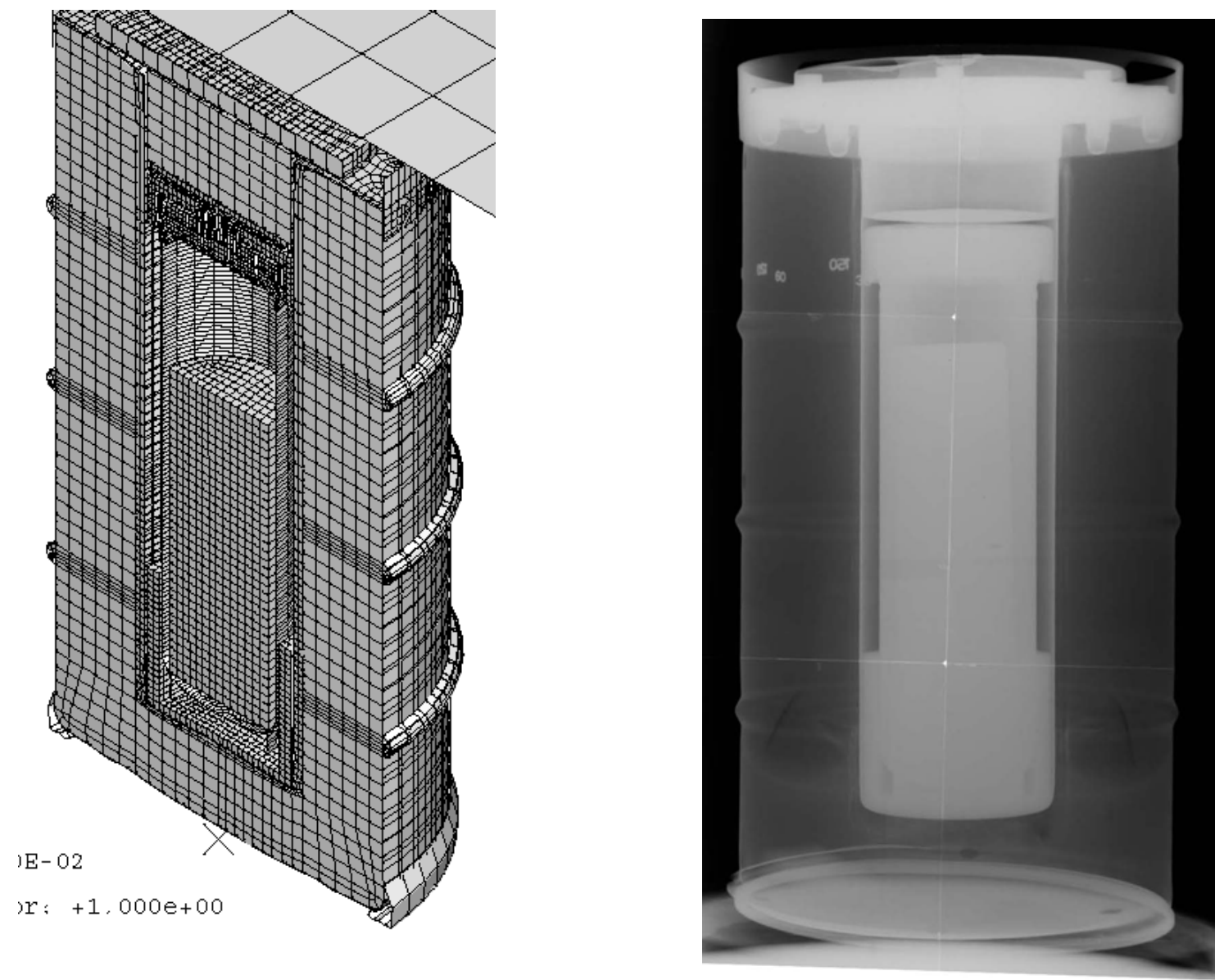